\title{
Relação entre Tecnologias da Informação e Comunicação e Criatividade: Revisão da Literatura
}

\author{
Daniela Vilarinho-Rezende \\ Universidade de Brasília, DF, Brasil. \\ Denise de Souza Fleith \\ Universidade de Brasília, DF, Brasil.
}

\author{
Clarissa Nogueira Borges \\ Universidade de Brasília, DF, Brasil. \\ Maria Cristina Rodrigues Azevedo Joly \\ Universidade de Brasília, DF, Brasil.
}

\begin{abstract}
Resumo: O objetivo deste estudo foi examinar, por meio de revisão de literatura de artigos empíricos e relatos de experiência, a produção científica sobre a relação entre uso das tecnologias da informação e comunicação (TICs) e criatividade no contexto da educação. A busca foi realizada nas bases de dados SciELO, Pepsic e Portal de Periódicos Capes, considerando as publicações no período de 2004 a 2014. Foram selecionados 28 artigos, distribuídos em 23 periódicos estrangeiros, que atenderam aos critérios de inclusão pré-estabelecidos. $\mathrm{O}$ ano com maior número de publicações foi $2012(n=6)$. Das pesquisas selecionadas, nenhuma foi realizada no Brasil. Os cenários de investigação foram educação básica, educação superior e formação de professores. Pesquisas com delineamento experimental foram conduzidas apenas no contexto da educação básica. Os estudos revisados examinaram uma diversidade de TICs e, de formageral, os resultados indicaram uma relação positiva entre tecnologia e desenvolvimento da criatividade no contexto educacional.
\end{abstract}

Palavras-chave: Criatividade, Tecnologia, Educação, Produção Científica.

\section{Relationship between Information and Communication Technologies and Creativity: Literature Review}

\begin{abstract}
The purpose of this study was to examine, through a literature review of empirical articles and experience reports, the scientific literature on the relationship between the use of Information and Communication Technologies (ICT) and creativity in the educational context. The search was conducted on the databases SciELO, Pepsic and Portal CAPES, considering the studies published from 2004 to 2014. According to the pre-established inclusion criteria, 28 articles, distributed in 23 foreign journals, were selected. The year with the highest number of publications was $2012(n=6)$. From the selected researches, none was conducted in Brazil. The investigation scenarios were basic education, higher education, and teacher professional training. Experimental design researches were conducted only in the basic education context. The reviewed studies evaluated a diversity of ICT and, in general, the results indicated a positive relationship between technology and creativity development in the educational context.
\end{abstract}

Keywords: Creativity, Technology, Education, Scientific Production. 


\title{
Relación entre las Tecnologías de la Información y Comunicación y Creatividad: Revisión de la Literatura
}

\begin{abstract}
Resumen: El objetivo de este estudio fue examinar, mediante la revisión de la literatura de artículos empíricos y relatos de experiencia, la producción científica acerca de la relación entre el uso de Tecnologías de la Información y Comunicación (TIC) y la creatividad en el contexto educativo. La búsqueda se realizó en las bases de datos SciELO, Pepsic y Portal de Periódicos CAPES, teniendo en cuenta los estudios publicados en el período de 2004 a 2014. Fueron seleccionados 28 artículos, distribuidos en 23 revistas extranjeras, que cumplieron los criterios de inclusión preestablecidos. El año con el mayor número de publicaciones fue $2012(n=6)$. De los estudios seleccionados, ninguno fue realizado en Brasil. Los escenarios de investigación fueron la educación básica, la educación superior y la formación del profesorado. Investigaciones con diseños experimentales se llevaron a cabo solo en el contexto de la educación básica. Los estudios revisados examinaron una diversidad de TIC y, en general, los resultados indicaron una relación positiva entre la tecnología y el desarrollo de la creatividad en el contexto educativo.

Palabras-clave: Creatividad, Tecnología, Educación, Producción Científica.
\end{abstract}

Os recursos tecnológicos associados à capacidade de representar e transmitir informação, denominados tecnologias da informação e comunicação (TICs), têm sido amplamente utilizados em diversos âmbitos de atividades humanas (Coll, \& Monereo, 2010). Martins (2005) afirma que distintas práticas sociais estão cada vez mais orientadas por e para essas tecnologias. Crianças e adolescentes que crescem na sociedade de hoje podem ser considerados nativos digitais, o que torna a integração das TICs na educação uma necessidade iminente para responder às demandas desses estudantes (Smith, 2012).

Besnoy e Clarke (2010) descrevem uma série de tecnologias digitais que vêm sendo utilizadas em sala de aula. A maioria desenvolveu-se graças à consolidação da Web 2.0, termo referente às propriedades atuais da internet que possibilitam o compartilhamento de informações e a interação entre usuários em tempo real. Exemplos de TICs empregadas na educação são: (a) ambientes virtuais: ambientes virtuais tridimensionais que simulam determinados aspectos do mundo real, como situações de trabalho, lazer ou educacionais (um dos exemplos mais conhecidos é o Second Life); (b) banco de dados: ferramenta utilizada para reunir e gerenciar dados, facilitando a pesquisa sobre determinado assunto; (c) Blog: página da internet regularmente atualizada, em que são publicados diversos conteúdos, como textos, imagens, músicas ou vídeos; em geral, há hiperlinks (recurso que permite a conexão com conteúdos de outras páginas ou documentos) e espaço para comentários dos leitores; (d) ferramentas de programação: ferramentas para criação de programas e aplicativos; (e) LMS (Learning Management Systems) ou SGA (Sistemas de Gestão da Aprendizagem): plataformas de ensino e aprendizagem a distância; (f) podcast. arquivos de áudio e/ou vídeo em formato digital compartilhados na internet; (g) softwares de edição de vídeos: programas de computador que possibilitam a criação e edição de vídeos utilizando recursos audiovisuais; (h) Wiki: site colaborativo que permite aos usuários alterarem informações de um documento.

Recursos de edição de texto e aparelhos para projeção de apresentações e exibição de filmes mantêm a mesma lógica dos recursos tradicionais e, por esse motivo, não promoveriam mudanças na forma de ensinar e aprender (Besnoy, \& Clarke, 2010). Dessa forma, a mera utilização de TICs em sala de aula não garante benefícios ao processo de ensino-aprendizagem (Cysneiro, 1999; Lalueza, Crespo, \& Camps, 2010; Valente, 2005). É necessário compreender e incorporar pedagogicamente as ferramentas tecnológicas na educação, pois as tecnologias da informação e comunicação, quando bem utilizadas, provocam alterações positivas na dinâmica educacional (Kenski, 2011). Alguns benefícios referem-se à ruptura nas hierarquias de poder em relação ao acesso à informação. Isso descentraliza o processo de ensino e aprendizagem da figura do professor, uma vez que permite aos alunos pesquisarem aquilo 
que lhes interessa, fortalecendo a independência e a autonomia. Outras vantagens dizem respeito à maior possibilidade de trocas de informações entre alunos e professores, interação entre pessoas de diferentes culturas e superação de barreiras espaço-temporais, ampliando o acesso à educação.

$\mathrm{O}$ uso de recursos tecnológicos também tem sido apontado como um elemento potencialmente facilitador da expressão criativa (Burkhardt, \& Lubart, 2010; Gangadharbatla, 2010; Lewis, 2009; Loveless, 2007; Rasinen et al., 2009). A criatividade, ou "capacidade de realizar uma produção que seja ao mesmo tempo nova e adaptada ao contexto na qual ela se manifesta" (Lubart, 2007, p. 16), é considerada um fenômeno complexo, multifacetado e plurideterminado (Alencar, \& Fleith, 2009; Nakano, \& Wechsler, 2012). Segundo abordagens teóricas sistêmicas, fatores relacionados ao indivíduo, como habilidades cognitivas, características de personalidade, nível de motivação e elementos do contexto familiar e social podem afetar o desenvolvimento e expressão do potencial criativo (Amabile, 1996; Csikszentmihalyi, 1999; Sternberg, \& Lubart, 1991). Nessa perspectiva, os diferentes sistemas sociais, como escola e família, exercem um papel significativo na promoção ou inibição da criatividade (Sawyer, 2012).

Em relação às características das tecnologias da informação e comunicação que poderiam facilitar o desenvolvimento e expressão da criatividade, Loveless (2007) destaca as seguintes: (a) caráter provisório, que permite aos usuários fazer mudanças e experimentar alternativas; (b) interatividade, que possibilita aos usuários se envolver em diversos níveis de interação; (c) capacidade e alcance, que facilitam o acesso a uma vasta quantidade de informações tanto local como em diferentes lugares; (d) velocidade e funções automáticas, que proporcionam armazenamento, transformação e exibição de informações e, assim, possibilitam aos usuários ler, observar, interrogar, interpretar, analisar e sintetizar as informações em níveis mais elevados.

A facilidade de acesso ao volume gigantesco de informações disponibilizadas por ferramentas de busca da internet, por exemplo, pode ser de grande valia na expansão do conhecimento e construção do saber. Entretanto, cabe ao usuário o exercício de escrutínio que garanta a qualidade e a diversidade das fontes, evitando acessar apenas os sites mais visitados ou que possuam contratos de publicidade que aumentem suas ocorrências. Esse problema é explorado por Burkhardt e Lubart (2010) em suas ponderações quanto ao emprego das tecnologias e sua influência na expressão da criatividade, em especial da originalidade. Os autores consideram, ainda, o risco de os indivíduos concentrarem sua atenção no uso da tecnologia em vez de focar no processo criativo. No contexto educacional, não são raros os casos em que ocorre o que Cysneiro (1999) denomina de inovação conservadora, ou uso das novas tecnologias digitais para realizar tarefas que poderiam ser feitas com a mesma eficiência por meio dos instrumentos tradicionais, como lápis e papel. De acordo com o autor, há muitos exemplos de inovação conservadora ao longo da história da tecnologia educacional, como computadores, transparências, filmes, televisão, rádio ou livros, textos com figuras, cores, desenhos e fotos em que a ênfase é no meio ao invés do conteúdo, mudando apenas a estética das práticas pedagógicas.

Nesse sentido, é fundamental que a incorporação de recursos tecnológicos na educação seja acompanhada de práticas pedagógicas que estimulem a criatividade (Ferguson, 2011; Hall, 2012; Loveless, 2007), tais como: valorização dos interesses e estilos de aprendizagem dos alunos; diversificação de técnicas instrucionais, tarefas e formas de avaliação; proposição de atividades que estimulem a imaginação, levem o aluno a produzir muitas ideias, a analisar uma situação sob diversos ângulos e a visualizar consequências para acontecimentos futuros (Alencar, \& Fleith, 2009; Renzulli, 2005; Wechsler, \& Souza, 2011). Além disso, é importante que o professor ensine de modo cooperativo, valorize as sugestões e questionamentos dos alunos, encoraje a produção de novas ideias e incentive a identificação e superação de obstáculos, a coragem de correr riscos e a tolerância à ambiguidade (Cropley, 2005). Ressalta-se, ainda, a necessidade de formação dos professores para uso criativo das TICs na educação. Joly, Silva e Almeida (2012), Kenski (2011), Lalueza et al. (2010) e Valente (2005) enfatizam que a capacitação deve contemplar não apenas as habilidades técnicas, mas também o desenvolvimento de competências para uso crítico dos recursos disponíveis e de como integrar a tecnologia à prática pedagógica. Esse último ponto ainda é um desafio. Silva et al. (2014) nomeiam essa habilidade de competência em gestão pedagógica que 
envolve as atitudes ou competências pedagógicas do professor frente à utilização das TICs como recurso didático, visando à aprendizagem dos alunos. Os autores ressaltam também a importância de o docente ter conhecimento das tecnologias digitais em relação à sua área de ensino. É preciso, portanto, aprofundar o conhecimento de como as TICs vêm sendo implementadas para fins educacionais em diferentes contextos e avaliar seus resultados.

Há de se considerar também que, para além da produção científica acerca da temática em questão, é imprescindível "analisar se esta representa uma contribuição efetiva para a área e se seu alcance e influência são viabilizados por veículos de divulgação de grande visibilidade". Para tanto, de acordo com Joly, Berberian, Andrade e Teixeira (2010), as pesquisas de metaciência em bancos de dados podem ser, por exemplo, as de levantamento das características da publicação, as de metanálise ou as análises realizadas por meio de escalas e questionários bibliométricos.

Dessa forma, dada a importância de se ter uma visão integrada e crítica do que foi produzido na literatura científica sobre tecnologias aplicadas à educação, tanto no Brasil quanto no exterior, bem como contribuir para melhor compreensão do papel das TICs em prol do desenvolvimento da criatividade em sala de aula, o objetivo deste estudo foi examinar a produção científica sobre a relação entre uso das TICs e criatividade no contexto da educação visando a sua caracterização no bojo da metaciência, por meio de uma revisão da literatura de artigos empíricos e relatos de experiência, publicados em periódicos científicos nos últimos 10 anos. A escolha desse intervalo de tempo justifica-se pela velocidade com que se alteram e evoluem as tecnologias digitais investigadas nos estudos aqui revisados.

\section{Método}

Este estudo foi construído a partir da análise de produções científicas, nacionais e internacionais que, de alguma forma, tratassem do uso das TICs no contexto educacional e que estivessem relacionadas à criatividade. Realizou-se revisão da literatura publicada no período de 2004 a 2014. As buscas foram realizadas nas bases de dados SciELO (Scientific Eletronic Library Online - Portal Regional), Pepsic (Periódicos Eletrônicos em Psicologia) e Portal de Periódicos
Capes, tendo como termos de busca, em português, criatividade, tecnologia e educação e, em inglês, creativity, technologye education.

\section{Composição da Amostra e Material}

A procura pelas produções científicas foi realizada no mês de julho de 2014 nas bases de dados SciELO, Pepsic e Portal de Periódicos Capes por serem referência e abrangerem produções nacionais e internacionais relacionadas à tecnologia, educação e criatividade. Como resultado dessa procura, foram localizadas 1.216 artigos, sendo $171(14,06 \%)$ relativos à pesquisa por meio dos termos de busca em português e $1.045(85,94 \%)$ referentes aos termos em inglês. Desses 1.216 artigos, $10(0,80 \%)$ foram extraídos da base de dados SciELO, quatro (0,30\%) da Pepsic e 1.202 (98,90\%) do Portal de Periódicos Capes. Após leitura e análise cuidadosa dos resumos, apenas 28 artigos (distribuídos em 23 periódicos estrangeiros), todos eles provenientes da base do Portal de Periódicos Capes e obtidos por meio da pesquisa com os termos de busca em inglês, foram selecionados de acordo com os critérios pré-estabelecidos e que atendiam os objetivos definidos para o presente estudo. Os critérios, para fins de inclusão, requeriam que o estudo avaliasse a implementação de alguma TIC em contexto educacional e seu efeito sobre o desenvolvimento da criatividade ou sobre a percepção acerca da criatividade em alunos ou professores. Além disso, era necessário que se tratasse de artigo empírico ou relato de experiência, uma vez que o objetivo era conhecer as experiências de uso das TICs. Quanto aos critérios de exclusão, consideraram-se estudos teóricos, de revisão de literatura e estudos em que a criatividade era considerada como consequência da TIC sem ter sido avaliada.

\section{Procedimentos}

Após realização da busca nos bancos de dados, os resumos dos artigos encontrados foram lidos e analisados de acordo com os critérios de inclusão e exclusão previamente citados. Em seguida, foi realizada a leitura completa apenas dos artigos que atenderam a esses critérios. A partir dessa leitura, foi feita uma análise rigorosa a partir de algumas categorias da metaciência, com o intuito de realizar uma 
caracterização geral dos artigos selecionados, como descrito por Joly et al. (2010). As categorias eleitas foram quantidade de publicação por ano, país em que foram coletados os dados, objetivo central de cada pesquisa e amostra selecionada. Em seguida, uma caracterização aprofundada de cada estudo foi realizada visando apresentar as tecnologias avaliadas, as medidas de criatividade utilizadas e os principais resultados encontrados nos artigos selecionados. Os resultados da caracterização geral dos artigos foram analisados por meio de estatística descritiva (frequência e porcentagem), com o intuito de expor o panorama geral das publicações selecionadas. Por outro lado, os resultados da caracterização aprofundada dos artigos foram apresentados de forma descritiva, com o objetivo de retratar ao leitor os principais dados das pesquisas analisadas.

\section{Resultados}

\section{Caracterização Geral dos Artigos Analisados}

$\mathrm{Na}$ categoria ano e quantidade de publicação, considerando o período analisado - 2004 a 2014 - o ano com maior participação foi 2012 com seis artigos (21,40\%), seguido de 2013 com cinco artigos (17,90\%), sendo que o período 2008 a 2010 apresentou igual quantidade de publicações - quatro (14,30\%). Em 2007 e 2011 foram publicados dois artigos $(7,10 \%)$ em cada ano e, em 2005, apenas um artigo (3,60\%). Nos anos de 2004, 2006 e 2014 não foram identificadas publicações relativas ao tema central deste estudo. Cabe destacar relativamente a 2014, a pesquisa abrangeu apenas o primeiro semestre. Nota-se um ligeiro aumento no número de publicações a partir do ano 2008 em comparação aos anos anteriores, seguido de uma relativa estabilidade ou manutenção desse número nos anos seguintes, com exceção de 2014. A Tabela 1 sintetiza esses achados.

Em relação ao país em que foram coletados os dados da pesquisa de cada artigo, ou seja, onde foi realizada a experiência de implementação das TICs, verifica-se uma maior concentração nos Estados Unidos da América (EUA) com sete artigos (25,00\%), seguido pelo Reino Unido com cinco artigos (19,90\%), Malásia com quatro artigos (14,30\%) e Taiwan com três (10, 70\%). Alemanha, Espanha, Itália, Eslovênia,
Turquia, Jordânia, Tailândia, China e Nigéria contribuíram, cada um, com um artigo. Vale ressaltar que não foi identificado nenhum artigo publicado no Brasil no que tange à temática investigada. Esses resultados são apresentados na Tabela 2.

Tabela 1

Distribuição de frequência e porcentagem dos artigos em função do ano de publicação.

\begin{tabular}{lcc}
\hline \multirow{2}{*}{ Ano de publicação } & \multicolumn{2}{c}{ Número de artigos } \\
\cline { 2 - 3 } & Frequência & Porcentagem \\
\hline 2004 & 0 & 0 \\
2005 & 1 & 3,57 \\
2006 & 0 & 0 \\
2007 & 2 & 7,14 \\
2008 & 4 & 14,29 \\
2009 & 4 & 14,29 \\
2010 & 4 & 14,29 \\
2011 & 2 & 7,14 \\
2012 & 6 & 21,42 \\
2013 & 5 & 17,86 \\
2014 & 0 & 0 \\
\hline Total & 28 & 100 \\
\hline
\end{tabular}

Tabela 2

Distribuição de frequência e porcentagem dos artigos em função do país em que foram coletados os dados.

\begin{tabular}{lcc}
\hline \multirow{2}{*}{ País } & \multicolumn{2}{c}{ Número de artigos } \\
\cline { 2 - 3 } & Frequência & Porcentagem \\
\hline EUA & 7 & 25,00 \\
Reino Unido & 5 & 17,86 \\
Malásia & 4 & 14,29 \\
Taiwan & 3 & 10,72 \\
Alemanha & 1 & 3,57 \\
China & 1 & 3,57 \\
Eslovênia & 1 & 3,57 \\
Espanha & 1 & 3,57 \\
Itália & 1 & 3,57 \\
Jordânia & 1 & 3,57 \\
Nigéria & 1 & 3,57 \\
Tailândia & 1 & 3,57 \\
Turquia & 1 & 3,57 \\
\hline Total & 28 & 100 \\
\hline
\end{tabular}


Quanto ao objeto central de cada pesquisa, houve uma grande variação. Apesar de todos os artigos avaliarem o aumento do nível de criatividade ou a percepção em relação ao seu desenvolvimento, vários tinham como foco principal a investigação da relação do uso de uma TIC com outra variável do contexto educacional. De forma geral, os estudos verificaram os seguintes temas: criatividade, processo criativo, criatividade tecnológica, criatividade na prática de ensino do professor, estudo religioso, redação, leitura e escrita, língua estrangeira, ciências, música, desenvolvimento e uso de games, interação com as TICs, formação de professores, competências no uso de tecnologias, educação inclusiva, sistema de avaliação de pares sobre produto do aluno, artes, preparação para atividades avaliativas. A amostra dos estudos analisados pode ser categorizada em três tipos: (a) alunos da educação básica ( $\mathrm{n}=16 ; 57,10 \%)$; (b) professores ou estudantes em formação para docência ( $\mathrm{n}=7 ; 25,00 \%)$ e (c) universitários ( $\mathrm{n}=5$; 17,90\%). A distribuição entre essas categorias de amostra, entretanto, não é uniforme, e educação básica foi o contexto com maior número de artigos.

\section{Caracterização Aprofundada dos Artigos Analisados}

Para apresentar uma descrição mais aprofundada dos artigos selecionados, os estudos foram divididos por tipo de amostra. Nessa caracterização, buscou-se analisar as tecnologias que vêm sendo investigadas e os principais resultados alcançados. Também foi destacada a multiplicidade de instrumentos de mensuração da criatividade para se investigar a temática.

\section{Alunos da educação básica}

A maioria das pesquisas encontradas nesta revisão da literatura foi realizada no contexto da educação básica (ver Tabela 3). Dezesseis artigos avaliaram o uso de diversas TICs como Facebook (Alias, Siraj, Daud, \& Hussin, 2013), websites (Chang, 2013; Jang, 2009), softwares (Chong, \& Lee, 2012; Leng, Ali, Mahmud, \& Baki, 2010; Nielsen, 2013; Pearson, 2005; Ward, 2009), vídeo digital (Goulah, 2007), CD-ROM (Mellor, 2008), game digital (Naeini, \& Masood, 2012; Navarrete, 2013; Ott, \& Pozzi, 2012), internet e material multimídia (Öngün, Altas, \& Demirag, 2011), ambiente de realidade virtual (Patera, Draperb, \& Naef, 2008) e portfólio online (Walsh, 2007).

A medida da influência das TICs variou entre as pesquisas: oito artigos investigaram apenas a percepção do aluno ou do pesquisador; três, além da percepção, avaliaram um produto desenvolvido pelo participante; dois analisaram o produto; outros dois, utilizaram o Teste de Pensamento Criativo de Torrance ou sua adaptação; e um combinou o uso de testes de criatividade com a avaliação do produto. Goulah (2007), Jang (2009), Leng et al. (2010), Mellor (2008), Öngün et al. (2011), Ott e Pozzi (2012), Pearson (2005) e Ward (2009) utilizaram diversos instrumentos para medir a percepção dos alunos quanto ao desenvolvimento da criatividade mediado pelas TICs. Entre esses instrumentos, podem ser citados os diários de campo do pesquisador; questionários, entrevistas e avaliações aplicadas aos participantes; dados das discussões online e das tarefas realizadas; diário de reflexão da professora; observações diretas ou filmagens da sala de aula; folha de monitoramento para codificar a observação em sala de aula; e gravações de áudio. Os resultados de todos esses estudos sugeriram que os participantes percebem as TICs como facilitadoras do desenvolvimento da criatividade.

Outros artigos, além de investigar a percepção dos participantes, analisaram os produtos dos alunos. Navarrete (2013), por exemplo, realizou uma entrevista semiestruturada, fez observação em sala de aula e teve acesso ao game digital desenvolvido pelo aluno, e concluiu que essa TIC favorece o processo criativo. Nielsen (2013) também fez uso de observação, entrevista com professores e alunos, questionário, e analisou os projetos e as composições elaboradas pelos participantes e mediadas por um software. Os resultados indicaram que essa tecnologia promoveu um ambiente para os alunos expressarem sua criatividade. Walsh (2007), por sua vez, verificou a expressão criativa dos estudantes por meio dos dados de entrevistas e avaliação de seus portfólios.

Chong e Lee (2012) optaram por avaliar o efeito de um software (StoryWorld) de aperfeiçoamento da escrita criativa por meio da redação do alunos, ou seja, do produto desenvolvido por eles. O StoryWorld era dividido em quatro módulos. Nos três primeiros, o aluno era introduzido a lições e exercícios acerca de elementos importantes para o desenvolvimento de uma história (cenário, personagens e progressão da 
Tabela 3

Descrição dos artigos selecionados considerando estudos com estudantes da educação básica.

\begin{tabular}{|c|c|c|c|}
\hline Referência & Participantes & TIC & Principais resultados \\
\hline \multicolumn{4}{|c|}{$1^{\circ}$ Ciclo do Ensino Fundamental } \\
\hline Chang (2013) & $\begin{array}{l}107 \text { alunos da } 4^{\mathrm{a}} \text { série } \\
\text { divididos em grupo } \\
\text { experimental (uso da } \\
\text { TIC) e controle }\end{array}$ & $\begin{array}{l}\text { Website com } \\
\text { atividades de } \\
\text { resolução de } \\
\text { problemas }\end{array}$ & $\begin{array}{l}\text { Grupo experimental apresentou escore maior } \\
\text { em criatividade do produto, elaboração e estilo. } \\
\text { Não houve diferença entre os grupos quanto } \\
\text { ao pensamento divergente, tendência criativa } \\
\text { e função. A análise qualitativa evidenciou que } \\
\text { os alunos chegaram a soluções refinando e } \\
\text { adaptando os pensamentos dos outros, por meio } \\
\text { de discussão ou interação na web. }\end{array}$ \\
\hline $\begin{array}{l}\text { Chong e Lee } \\
(2012)\end{array}$ & $\begin{array}{l}17 \text { alunos da educação } \\
\text { primária }\end{array}$ & $\begin{array}{l}\text { Software- } \\
\text { StoryWorld }\end{array}$ & $\begin{array}{l}\text { Média do escore no pós-teste de escrita criativa } \\
\text { foi significativamente maior que no pré-teste, ou } \\
\text { seja, o StoryWorld foi efetivo. }\end{array}$ \\
\hline $\begin{array}{l}\text { Naeini e } \\
\text { Masood } \\
(2012)\end{array}$ & $\begin{array}{l}91 \text { alunos das } 3^{\mathrm{a}} \text { e } 4^{\mathrm{a}} \\
\text { séries }\end{array}$ & $\begin{array}{l}\text { Game Digital - I } \\
\text { Spy, Treasure } \\
\text { Hunt }\end{array}$ & $\begin{array}{l}\text { Houve aumento significativo dos escores } \\
\text { em fluência, originalidade e flexibilidade } \\
\text { comparando os resultados antes e depois a } \\
\text { implementação da TIC. Entretanto, não houve } \\
\text { diferença quanto à elaboração. }\end{array}$ \\
\hline $\begin{array}{l}\text { Patera et al. } \\
(2008)\end{array}$ & $\begin{array}{l}13 \text { alunos da educação } \\
\text { primária }\end{array}$ & $\begin{array}{l}\text { Ambiente de } \\
\text { realidade virtual } \\
\text { - sistema de } \\
\text { projeção semi- } \\
\text { imersiva }\end{array}$ & $\begin{array}{l}\text { Embora os alunos que passaram pela } \\
\text { experiência virtual tenham apresentado alto } \\
\text { nível de motivação, o mesmo não ocorreu em } \\
\text { relação à criatividade de suas redações. }\end{array}$ \\
\hline $\begin{array}{l}\text { Ott e Pozzi } \\
(2012)\end{array}$ & $\begin{array}{l}\text { Cerca de } 40 \text { alunos ao } \\
\text { longo de } 3 \text { anos - da } 3^{\text {a }} \\
\text { a } 5^{\text {a }} \text { série }\end{array}$ & $\begin{array}{l}45 \text { Games } \\
\text { Digitais - Master } \\
\text { Mind, Minefield, } \\
\text { Battleship, } \\
\text { Domino, } \\
\text { Labyrinths } \\
\text { etc. }\end{array}$ & $\begin{array}{l}\text { A criatividade pode ser, em certa medida, } \\
\text { promovida e reforçada por meio de ferramentas } \\
\text { de TIC. Indicadores de criatividade relativos à } \\
\text { afetividade são os mais presentes, seguidos dos } \\
\text { de metacognição e cognição. Considerando os } \\
\text { três anos do experimento, houve um aumento de } \\
\text { todos os indicadores a cada ano. }\end{array}$ \\
\hline $\begin{array}{l}\text { Pearson } \\
(2005)\end{array}$ & Alunos de 10 anos & $\begin{array}{l}\text { Software editor } \\
\text { de vídeo - } \\
\text { Pinnacle Studio }\end{array}$ & $\begin{array}{l}\text { Alunos apresentaram três tipos de interação com } \\
\text { o software. complacente, criativo e desestruturado. } \\
\text { Todas as crianças apresentavam esses três tipos ao } \\
\text { longo das semanas interagindo com o computador, } \\
\text { mas quando o prazo de entrega do trabalho foi } \\
\text { chegando ao final, a maioria assumiu o tipo } \\
\text { complacente ou criativo para terminar o trabalho. }\end{array}$ \\
\hline \multicolumn{4}{|c|}{$2^{\circ}$ Ciclo do Ensino Fundamental } \\
\hline $\begin{array}{l}\text { Navarrete } \\
(2013)\end{array}$ & $\begin{array}{l}12 \text { alunos da } 6^{\mathrm{a}}, 7^{\mathrm{a}} \\
\text { e } 8^{\mathrm{a}} \text { séries com } 1,2 \\
\text { e } 3 \text { anos de curso } \\
\text { respectivamente }\end{array}$ & $\begin{array}{l}\text { Game Digital - } \\
\text { programas de } \\
\text { criação de games }\end{array}$ & $\begin{array}{l}\text { Alunos perceberam que o desenvolvimento de } \\
\text { games favorece o processo criativo. }\end{array}$ \\
\hline Jang (2009) & 31 alunos da $7^{\text {a }}$ série & $\begin{array}{l}\text { Website como } \\
\text { material } \\
\text { de estudo } \\
\text { suplementar }\end{array}$ & $\begin{array}{l}\text { Fluência, sensibilidade, flexibilidade, } \\
\text { originalidade e elaboração foram desenvolvidas. } \\
\text { A maioria dos alunos preferiu o ensino online, } \\
\text { porque era inovador e interessante para eles. }\end{array}$ \\
\hline $\begin{array}{l}\text { Leng et al. } \\
(2010)\end{array}$ & $\begin{array}{l}34 \text { alunos da } 7^{\text {a }} \text { série para } \\
\text { o grupo experimental } \\
\text { (uso da TIC) e } 35 \text { para } \\
\text { o grupo controle com } \\
\text { idade entre } 13 \text { e } 14 \text { anos }\end{array}$ & $\begin{array}{l}\text { Software-Game } \\
\text { Maker }\end{array}$ & $\begin{array}{l}\text { Grupo experimental avaliou de forma } \\
\text { significativamente mais positiva as dimensões } \\
\text { do processo criativo quando comparado ao } \\
\text { grupo controle. }\end{array}$ \\
\hline
\end{tabular}

Continua 


\begin{tabular}{|c|c|c|c|}
\hline Mellor (2008) & $\begin{array}{l}8 \text { alunos do ensino } \\
\text { fundamental entre } 13 \text { e } \\
15 \text { anos }\end{array}$ & $\begin{array}{l}\text { CD-ROM - Dance } \\
\text { eJay }\end{array}$ & $\begin{array}{l}\text { Criatividade foi evidenciada em todas as } \\
\text { respostas de composição, independentemente } \\
\text { das origens musicais dos participantes e de suas } \\
\text { experiências anteriores de aula formal de música } \\
\text { instrumental. }\end{array}$ \\
\hline Walsh (2007) & $\begin{array}{l}7 \text { alunos ( } 1^{\mathrm{a}} \text { e } 2^{\mathrm{a}} \\
\text { geração de imigrantes } \\
\text { chineses), } 3 \text { websites } \\
\text { criados por eles }\end{array}$ & $\begin{array}{l}\text { Portfólio online - } \\
\text { website }\end{array}$ & $\begin{array}{l}\text { Os websites foram criados de uma forma nunca } \\
\text { feita antes. O website grupal ganhou o primeiro } \\
\text { lugar na competição de web design New York City } \\
\text { ThinkQuest. }\end{array}$ \\
\hline $\begin{array}{l}\text { Öngün et al. } \\
\text { (2011) }\end{array}$ & 435 alunos da $8^{\mathrm{a}}$ série & $\begin{array}{l}\text { Internet e } \\
\text { material } \\
\text { multimídia }\end{array}$ & $\begin{array}{l}75,90 \% \text { disseram que a experiência favoreceu a } \\
\text { criatividade. }\end{array}$ \\
\hline \multicolumn{4}{|c|}{ Ensino Médio } \\
\hline $\begin{array}{l}\text { Alias et al. } \\
(2013)\end{array}$ & $\begin{array}{l}40 \text { alunos para grupo } \\
\text { experimental (uso da } \\
\text { TIC) e } 40 \text { alunos para } \\
\text { grupo controle }\end{array}$ & Facebook & $\begin{array}{l}\text { Grupo experimental apresentou índices de } \\
\text { criatividade maiores que o grupo controle. }\end{array}$ \\
\hline Goulah (2007) & $\begin{array}{l}8 \text { alunos entre } 16 \text { e } 18 \\
\text { anos }\end{array}$ & Vídeo Digital & $\begin{array}{l}\text { Alunos afirmaram que o uso do vídeo digital } \\
\text { facilitou a expressão criativa. }\end{array}$ \\
\hline Ward (2009) & $\begin{array}{l}189 \text { alunos da educação } \\
\text { secundária }\end{array}$ & $\begin{array}{l}\text { Softwares } \\
\text { de criação/ } \\
\text { composição de } \\
\text { sons e músicas }\end{array}$ & $\begin{array}{l}\text { A TIC favoreceu a criatividade. Os alunos } \\
\text { passaram a usar a TIC como uma ferramenta } \\
\text { para articular suas ideias. }\end{array}$ \\
\hline Nielsen (2013) & $\begin{array}{l}2 \text { professoras e } 10 \\
\text { alunos }\end{array}$ & $\begin{array}{l}\text { Software } \\
\text { de ensino e } \\
\text { composição de } \\
\text { músicas }\end{array}$ & $\begin{array}{l}\text { Promoção de um ambiente favorecedor para o } \\
\text { desenvolvimento da criatividade dos alunos. }\end{array}$ \\
\hline
\end{tabular}

história). Ao concluir essas fases, era desbloqueado o quarto módulo em que o aluno criava sua própria história. O professor tinha acesso a todas as etapas e fornecia feedback sobre gramática, ortografia e criatividade. Ao final, a história poderia ser compartilhada com os colegas. Os resultados indicaram que o nível de criatividade das redações dos participantes aumentou em relação a sua produção anterior ao uso da TIC. O mesmo não ocorreu no estudo de Patera et al. (2008) que também avaliou como produto a redação feita pelos participantes. Os alunos foram submetidos a um ambiente de realidade virtual com o intuito de estimular sua imaginação e aumentar sua motivação em uma atividade posterior de redação sobre o contexto vivenciado em tal ambiente virtual. Os achados indicaram que esses alunos apresentaram níveis de criatividade inferiores àqueles que não fizeram uso de tal tecnologia.

Outros autores fizeram uso de teste de criatividade, uma medida já validada pela literatura da área. Alias et al. (2013), que utilizaram o Teste de Pensamento Criativo de Torrance adaptado, verificaram que os alunos que fizeram uso do Facebook como prática pedagógica para o ensino religioso obtiveram maiores índices de criatividade que aqueles que tiveram aulas tradicionais. Já os resultados do estudo de Naeini e Masood (2012), que utilizaram o teste em sua versão original, indicaram que o uso de games digitais aumentou os índices de fluência, flexibilidade e originalidade quando comparados à aplicação anterior à implementação da TIC em sala de aula. O nível de elaboração não apresentou diferença significativa entre $\mathrm{o}$ antes e depois.

Chang (2013) utilizou testes de criatividade (Technological Creativity Test, de Yeh, e The Williams Creative Thinking Test) e uma escala para avaliar o produto, no caso a construção de um modelo de carro elétrico (Creative Product Scale, de Chang). Os resultados indicaram que os alunos que tiveram aula com atividades online de resolução de problemas em um website obtiveram maiores escores na criatividade do produto, no índice de elaboração e de estilo, e em criatividade tecnológica. Porém, não houve diferença significativa entre esses alunos e os que tiveram aula quanto ao 
pensamento divergente e a tendências criativas entre esses alunos e os que tiveram aula tradicional.

\section{Universitários}

Nesta revisão da literatura, foram encontrados cinco artigos em que o objetivo era investigar a influência das TICs no desempenho criativo de estudantes universitários (ver Tabela 4). Entre esses estudos, foi encontrada uma variedade de TICs, tais como o computador (Abass, 2011), diferentes softwares (Chen, 2012; Christ, Weber, \& Sato, 2012; Eyadat, \& Eyadat, 2010) e o iPod (Dale, 2008). A forma de medir a criatividade, apesar dos diferentes instrumentos utilizados, foi predominantemente a partir da percepção dos alunos em relação ao seu desempenho ou a visão de seus professores. Nos estudos de Christ et al. (2012), Dale (2008) e Eyadat e Eyadat, (2010), houve a utilização de instrumentos como questionário, entrevista semiestruturada e grupo focal, e escala respectivamente. Na pesquisa de Chen (2012), cujo objetivo era compreender como ocorria o processo criativo de alunos de música ao fazerem composições mediadas pelo computador, além de analisar os diários dos estudantes e realizar entrevistas semiestruturadas, foi avaliado o processo criativo por meio da construção do produto, no caso, a composição.

Um teste de habilidade criativa foi utilizado para medir a criatividade de estudantes de artes por Abass (2011). Nesse estudo, o autor desenvolveu o Creative Ability Test (CAT) e o utilizou para comparar o desempenho de alunos que tiveram aulas mediadas por computador com o de estudantes que não tiveram acesso a essa TIC durante suas aulas. Enquanto os outros quatro estudos (Chen, 2012; Christ et al., 2012; Dale, 2008; Eyadat, \& Eyadat, 2010) alcançaram resultados positivos quanto ao uso de tecnologias digitais para o desenvolvimento da criatividade, os resultados de Abass (2011) não se mostraram favoráveis, uma vez que não houve diferença significativa entre o grupo que fez uso do computador e o que não fez.

\section{Professores ou estudantes em formação para docência \\ No contexto de aperfeiçoamento de práticas} docentes ou formação de novos professores, foram encontradas sete produções científicas (ver Tabela 5). A única TIC investigada em mais de um estudo foi o portfólio online (Na, \& Wilder, 2010; Johnson-Leslei, 2008-2009). Os outros cinco artigos avaliaram o

Tabela 4

Descrição dos artigos selecionados considerando estudos com universitários.

\begin{tabular}{|c|c|c|c|}
\hline Referência & Participantes & TIC & Principais resultados \\
\hline Abass (2011) & $\begin{array}{l}48 \text { universitários da área de } \\
\text { artes (escultura) divididos } \\
\text { em grupo experimental } \\
\text { (uso da TIC) e controle }\end{array}$ & Computador & $\begin{array}{l}\text { Não houve diferença significativa entre o } \\
\text { grupo experimental e controle em relação ao } \\
\text { escore em criatividade. }\end{array}$ \\
\hline Chen (2012) & 3 estudantes de graduação & $\begin{array}{l}\text { Software de } \\
\text { composição de } \\
\text { música }\end{array}$ & $\begin{array}{l}\text { A TIC teve um impacto direto e positivo } \\
\text { durante o processo criativo de composição } \\
\text { de música dos alunos. }\end{array}$ \\
\hline $\begin{array}{l}\text { Christ et al. } \\
\text { (2012) }\end{array}$ & $\begin{array}{l}25 \text { alunos universitários de } \\
\text { Psicologia }\end{array}$ & $\begin{array}{l}\text { Software- } \\
\text { EREP } 2.0\end{array}$ & $\begin{array}{l}\text { EREP } 2.0 \text { favoreceu a experiência criativa dos } \\
\text { alunos na criação de dicas para preparação } \\
\text { de atividades avaliativas. }\end{array}$ \\
\hline Dale (2008) & $\begin{array}{l}\text { Instrutores dos projetos } \\
\text { e líderes dos projetos } \\
\text { (avaliando o uso da TIC } \\
\text { pelos alunos de graduação) }\end{array}$ & $\begin{array}{l}\text { iPod-áudio, } \\
\text { imagem e texto }\end{array}$ & $\begin{array}{l}\text { Os alunos exploraram o tema estudado } \\
\text { de forma original, ultrapassando as } \\
\text { barreiras do tema, e de maneiras que } \\
\text { antes consideravam difícil. Permitiu uma } \\
\text { aprendizagem mais flexível, profunda } \\
\text { e uma abordagem personalizada para a } \\
\text { aprendizagem e ao mesmo tempo motivou } \\
\text { intrinsecamente os alunos. }\end{array}$ \\
\hline $\begin{array}{l}\text { Eyadat e Eyadat, } \\
(2010)\end{array}$ & $\begin{array}{l}42 \text { universitários para grupo } \\
\text { experimental (uso da TIC) e } \\
41 \text { para grupo controle }\end{array}$ & Softwares & $\begin{array}{l}\text { Grupo experimental teve médias maiores em } \\
\text { criatividade e nas subescalas após o uso das } \\
\text { tecnologias. }\end{array}$ \\
\hline
\end{tabular}


uso de editor de vídeo (Arnald, Padilla, \& Tunhikorn, 2009), editor de games digitais (Frossard, Barajas, \& Trifonova, 2012), ferramentas da web 2.0 (Magnuson, 2013), ambiente de aprendizagem virtual (Starcic, 2010) e sistema online de avaliação por pares (Tsai, \& Liang, 2009).

As medidas de criatividade utilizadas também variaram nesse contexto. Parte dos artigos avaliou a percepção dos participantes quanto ao desenvolvimento da criatividade mediado pela tecnologia. An e Wilder (2010) investigaram por meio de questionário com questões abertas e fechadas os benefícios e os entraves do uso do portfólio online por professores em formação. Como resultado, o maior benefício relatado pelos participantes foi o favorecimento da expressão criativa. Johson-Leslei (2008-9) também utilizou um questionário para comparar dois sistemas de criação de portfólio e verificou que um deles permitia um maior nível de criatividade por apresentar comandos mais flexíveis. Magnuson (2013) também se valeu da percepção de seus participantes ao investigar o uso de quatro ferramentas da web 2.0 no contexto educacional. Foram utilizados questionários, notas de campo, discussões online e e-mails. Os resultados revelaram que apenas duas ferramentas estimulavam a criatividade de seus usuários.

Outra parte dos estudos investigou a percepção dos participantes e avaliou os produtos produzidos por eles. Arnald et al. (2009), ao avaliarem o desenvolvimento de habilidades em TICs por parte de professores em formação, utilizaram observação da sala de aula, questionários, discussão online e análise do vídeo produzido. Frossard et al. (2012), com o objetivo de aperfeiçoar as habilidades criativas de professores,

Tabela 5

Descrição dos artigos selecionados considerando estudos com professores ou estudantes em formação para a docência.

\begin{tabular}{|c|c|c|c|}
\hline Referência & Participantes & TIC & Principais resultados \\
\hline $\begin{array}{l}\text { An e Wilder } \\
(2010)\end{array}$ & $\begin{array}{l}37 \text { estudantes de um curso de } \\
\text { formação para professores }\end{array}$ & $\begin{array}{l}\text { Portfólio } \\
\text { online- } \\
\text { Blackboard } \\
\text { e portfolio } \\
\text { system }\end{array}$ & $\begin{array}{l}\text { Expressão da criatividade foi o maior } \\
\text { benefício relatado pelos participantes. }\end{array}$ \\
\hline $\begin{array}{l}\text { Arnald et al. } \\
\text { (2009) }\end{array}$ & $\begin{array}{l}18 \text { professores de ciência em } \\
\text { formação }\end{array}$ & $\begin{array}{l}\text { Editor de vídeo } \\
\text { - Windows } \\
\text { Movie Maker }\end{array}$ & Favoreceu o uso de habilidades criativas. \\
\hline $\begin{array}{l}\text { Frossard et al. } \\
\text { (2012) }\end{array}$ & $\begin{array}{l}16 \text { professores da educação } \\
\text { primária e secundária, } 3 \text { games e } \\
\text { outros } 4 \text { professores e } 46 \text { alunos } \\
\text { que utilizaram os games } \\
\text { desenvolvidos e os avaliaram }\end{array}$ & $\begin{array}{l}\text { Game- Easy- } \\
\text { to-use game } \\
\text { editors }\end{array}$ & $\begin{array}{l}\text { Houve a promoção da criatividade } \\
\text { no processo, no produto e em sua } \\
\text { implementação. }\end{array}$ \\
\hline $\begin{array}{l}\text { Johnson- } \\
\text { Leslie(2008-9) }\end{array}$ & $\begin{array}{l}17 \text { alunos universitários em } \\
\text { uma classe de tecnologia } \\
\text { educacional }\end{array}$ & $\begin{array}{l}\text { Portfólio } \\
\text { online- } \\
\text { College } \\
\text { LiveText e } \\
\text { HyperStudio }\end{array}$ & $\begin{array}{l}\text { Futuros professores preferiram a alta } \\
\text { eficácia das aplicações do HyperStudio } \\
\text { quando comparado ao College LiveText, } \\
\text { devido a sua flexibilidade que combinava } \\
\text { com a criatividade, visão e estilo do } \\
\text { participante. }\end{array}$ \\
\hline $\begin{array}{l}\text { Magnuson } \\
(2013)\end{array}$ & $\begin{array}{l}17 \text { pós-graduandos do curso } \\
\text { online sobre alfabetização/ } \\
\text { biblioteconomia }\end{array}$ & $\begin{array}{l}\text { Ferramentas } \\
\text { da Web 2.0: } \\
\text { Glogster, } \\
\text { PBworks, Diigo } \\
\text { e Prezi }\end{array}$ & $\begin{array}{l}\text { A natureza visual da Glogster e Prezi levou } \\
\text { muitos estudantes a mencionarem essas } \\
\text { ferramentas como sendo divertidas e } \\
\text { criativamente estimulantes. PBworks e } \\
\text { Diigo não foram associadas à criatividade. }\end{array}$ \\
\hline Starcic (2010) & 43 professores em formação & $\begin{array}{l}\text { Ambiente de } \\
\text { aprendizagem } \\
\text { virtual - } \\
\text { SEVERI }\end{array}$ & $\begin{array}{l}\text { Quanto aos indicadores de criatividade } \\
\text { (apresentação e comunicação multimodal, } \\
\text { imaginação e originalidade), os alunos } \\
\text { obtiveram bons resultados. }\end{array}$ \\
\hline $\begin{array}{l}\text { Tsai e Liang, } \\
(2009) \\
886\end{array}$ & 36 professores em formação & $\begin{array}{l}\text { Sistema online } \\
\text { de avaliação } \\
\text { por pares }\end{array}$ & $\begin{array}{l}\text { A avaliação online dos colegas ao longo de três } \\
\text { etapas permitiu o aperfeiçoamento do nível de } \\
\text { criatividade requerida ao aluno na atividade } \\
\text { criada pelo professor }\end{array}$ \\
\hline
\end{tabular}


propuseram o uso de um editor de criação de games como tecnologia para alcançar tal fim. Como forma de avaliar a intervenção, os autores utilizaram questionário para os professores analisarem seu processo criativo, outro para os participantes e experts em games julgarem o produto criativo e, por fim, a implementação do game em sala de aula foi investigada por meio de observação e entrevista com o professor e os alunos que utilizaram a TIC. O resultado em ambos os artigos foi favorável ao desenvolvimento da criatividade.

Starcic (2010), que também utilizou como dado de pesquisa a percepção dos professores em formação e o produto produzido por eles, fez uso de seus diários de reflexão, grupos focais, o projeto de trabalho do professor (plano de aula e material de ensino) e os seus ensaios. Todos esses dados foram codificados para responder as questões de pesquisa. No que diz respeito à criatividade dos participantes, foram obtidos bons resultados em relação à apresentação e comunicação multimodal e também em relação à imaginação e à originalidade.

Dos sete estudos aqui selecionados, apenas um utilizou a avaliação do produto como medida de criatividade. Tsai e Liang (2009) investigaram um sistema online de avaliação dos pares, ou seja, o uso de uma ferramenta digital que permite o acesso ao trabalho de seu colega e a troca de feedbacks relativos a esse produto. A partir de critérios pré-estabelecidos, cada participante indicava uma nota de 1 a 7 para a atividade de ciências planejada pelos participantes e destinada a alunos da pré-escola e acrescentava alguns comentários. Os resultados indicaram que, depois de três ciclos de avaliações, houve uma melhora quanto ao nível de criatividade que a atividade requeria dos alunos.

\section{Discussão}

Em síntese, por meio desta revisão da literatura, que buscou examinar a produção científica sobre a relação entre uso das TICs e criatividade no contexto da educação, foram selecionados 28 artigos distribuídos em 23 periódicos, sendo que todos estes se encontravam no Portal de Periódicos CAPES. Diante desses dados, vale ressaltar dois aspectos do estado da arte dessa temática. Primeiro, o número de artigos é relativamente baixo considerando a importância do tema. Os números não demonstraram haver uma tendência crescente de publicações na área ao longo do período investigado. Esses achados parecem indicar um desinteresse da área científica pelo tema, entretanto, não se pode afirmar que tal fato reflita uma decadência da temática específica, pois o processo de implementação das tecnologias digitais na educação está em desenvolvimento e estas ainda não foram totalmente incorporadas e adaptadas ao contexto de ensino e aprendizagem nas instituições educacionais (Valente, 2014). Ao lado disso, a criatividade é um fenômeno que encontra resistência dentro do sistema educacional (Mueller, Melwani, \& Goncalo, 2010). De acordo com Kaufman e Beghetto (2013), apesar dos benefícios para a aprendizagem, para saúde mental e física, para sucesso acadêmico e profissional e para o progresso mundial, a criatividade também tem seus custos - requer tempo e recursos das instituições e dos profissionais que se dispõem a desenvolvê-la em seus alunos. A hipótese é que os estudos sobre as tecnologias digitais ainda estejam mais focados em analisar seu efeito em termos de desempenho acadêmico dos estudantes e, sendo investigações de natureza experimental ou quase-experimental, inviabilizam, muitas vezes, a análise conjunta de outras varáveis, como a criatividade (Kenski, 2011). É fato que as tecnologias têm sido utilizadas amplamente nas atividades de toda a população (Coll, \& Monereo, 2010) e a criatividade é uma habilidade altamente requisitada no contexto atual que está em constante mudança (Alencar, \& Fleith, 2009). Também é fato que crianças e adolescentes, que são considerados nativos digitais, demandam a integração dessas tecnologias na educação (Smith, 2012). Dessa forma, acredita-se que a produção científica sobre a relação entre o uso das TICs e a criatividade no contexto da educação crescerá nos próximos anos, sendo pois destacada no presente estudo sua necessidade.

Um segundo aspecto refere-se ao acesso restrito ao Portal de Periódicos Capes e, algumas vezes, ao texto completo de artigos publicados nos periódicos. Apesar disso não ter afetado o presente estudo, dificulta a disseminação dos resultados encontrados, comprometendo o desenvolvimento da área de pesquisa acerca do tema e do efeito desta sobre a prática educacional mediada pelas TICs. Entretanto, outras fontes de pesquisa, como o Google Acadêmico, podem suprir, em parte, essa lacuna, uma vez que apresenta um número considerável de artigos com acesso ao texto completo. A preocupação em destacar o fato de que o Portal da Capes não está disponível ao público em geral deve-se à necessidade de que os 
resultados das pesquisas subsidiem a prática, contribuindo para a sua manutenção, reformulação ou modificação em prol do bem estar subjetivo e social.

Os resultados também revelaram não haver pesquisas relativas à relação entre TICs e criatividade no Brasil considerando as bases de dados investigadas. Os países asiáticos, EUA e Reino Unido lideram o número de publicações. Esse aspecto assinala urgência quanto ao incentivo e prioridade das agências de fomento para a área das TIC e criatividade na Psicologia e Educação visando uma expressiva produção científica brasileira como reflexo de uma real preocupação com a qualidade da educação no Brasil. Essa afirmação baseia-se na percepção da importância de o processo de ensino e aprendizagem dar-se em um ambiente criativo como afirmam Ferguson (2011), Hall (2012), Loveless (2007), entre outros autores.

Um aspecto positivo relacionado aos artigos selecionados foi a constatação de que no contexto educacional as TICs têm sido utilizadas com vistas ao desenvolvimento da criatividade de professores, professores em formação, estudantes universitários e alunos do ensino básico. Vale ressaltar, portanto, a relevância de se investigar diferentes tipos de fatores que possam influenciar a criatividade em todas essas amostras. Em uma revisão da literatura sobre programas de treinamento em criatividade realizada por Nakano (2011), foi demonstrado que a habilidade criativa pode ser desenvolvida nos diferentes graus acadêmicos.

Quanto à caracterização mais aprofundada das produções científicas, podemos destacar a grande variedade de TICs que têm sido implementadas em sala de aula como, por exemplo, softwares, redes sociais, games, portfólios online, websites, ambiente de realidade virtual, entre outros que foram apresentados na descrição dos artigos. Essa diversidade também reflete a forma como essa área de pesquisa têm se constituído. Apesar de alguns estudos investigarem uma mesma categoria de tecnologia (por exemplo, softwares, redes sociais, ou games), esta é implementada em contextos totalmente diferentes como, por exemplo, o uso de um software para desenvolver a redação criativa de alunos (por exemplo, Leng et al., 2010) e outro software para edição de vídeos com o intuito de investigar a relação entre a tecnologia e o estudante (Pearson, 2005). Os estudos, em sua maioria, avaliam experiências pontuais, o que dificulta a generalização daquela ferramenta para outros contextos. Vale ressaltar a importância de avaliar o objetivo pedagógico que se pretende alcançar e se as características das TICs favorecem tal meta. O estudo de Patera et al. (2008), em que a experiência do ambiente de realidade virtual aumentou o nível de motivação do alunos, mas não o de criatividade, é um exemplo disso. Essa pesquisa sinaliza que é necessário um bom planejamento ao usar tecnologias para determinados fins. As TICs podem apresentar potencial para estimular o desenvolvimento de comportamentos criativos. Entretanto, é preciso que sejam bem empregadas considerando o contexto e os objetivos a serem atingidos. Na realidade, é necessário preparar os educadores para utilizarem essas ferramentas de forma intencional.

Outro aspecto que merece destaque é a diversidade de instrumentos utilizados para mensurar a influência da TIC sobre a criatividade. Esse fato também dificulta a comparação dos resultados de cada pesquisa. A despeito dessas dificuldades, de forma geral, os estudos empíricos e os relatos de experiência confirmaram o que alguns teóricos já defendiam (por exemplo Burkhardt, \& Lubart, 2010; Loveless, 2007) - as TICs favorecem o desenvolvimento da criatividade.

Os resultados dos estudos revisados revelam ganhos em distintas medidas de criatividade, considerando as diferentes amostras investigadas, a partir do uso intencional e pedagógico de TICs no processo de ensino-aprendizagem. Vale destacar que apenas na amostra de educação básica há artigos que descrevem pesquisas experimentais ou exploratórias. Os artigos com universitários e docentes referem-se basicamente à percepção e opinião dos participantes acerca do uso das TICs e a relação com criatividade.

A partir dos resultados aqui apresentados e discutidos, deve-se destacar a necessidade de se incentivar pesquisas na área, em especial no cenário brasileiro. Por fim, sugere-se que as pesquisas busquem utilizar metodologias que permitam a comparação entre diferentes tecnologias e que os resultados possam ser generalizados para contextos menos restritos. Também é importante que pesquisas futuras busquem investigar quais são as características específicas das TICs que são mais efetivas e como elas afetam o desenvolvimento da criatividade. Como limitação do estudo, pode ser apontada a não inclusão de pesquisas resultantes de dissertações de mestrado e teses de doutorado que não tenham sido formatadas em artigos. 


\section{Referências}

Abass, B. T. (2011). Computer instructional approach and students' creative ability in sculpture education in Nigeria universities: Obafemi Awolowo University as a case study. World Journal of Education, 1(2), 130-135. doi:10.5430/wje.v1n2p130

Alencar, E. M. L. S., \& Fleith, D. S. (2009). Criatividade: múltiplas perspectivas (3a ed.). Brasília, DF: Ed. UnB.

Alias, N., Siraj, S., Daud, M. K. A., \& Hussin, Z. (2013). Effectiveness of facebook based learning to enhance creativity among Islamic studies students by employing Isman Instructional Design Model. The Turkish Online Journal of Educational Technology, 12(1), 60-67. Recuperado de http://www.tojet.net/ articles/v12i1/1217.pdf

Amabile, T. (1996). Creativity in context. Boulder, CO: Westview.

An, H., \& Wilder, H. (2010). A bottom-up approach for implementing electronic portfolios in a teacher education program. Journal of Digital Learning in Teacher Education, 26(3), 84-91. Recuperado de http://files.eric.ed.gov/fulltext/EJ881730.pdf

Arnald, S. R., Padilla, M. J., \& Tunhikorn, B. (2009). The development of pre-service science teachers' professional knowledge in utilizing ICT to support professional lives. Eurasia Journal of Mathematics, Science \& Technology Education, 5(2), 91-101. doi:10.12973/eurasia.2009.00132a

Besnoy, K. D., \& Clarke, L. W. (2010). High-tech teaching success! A step-by-step guide to using innovative technology in your classroom. Waco, TX: Prufrock.

Burkhardt, J. M., \& Lubart, T. (2010). Creativity in the age of emerging technology: some issues and perspectives in 2010. Creativity and Innovation Management, 19(2), 160-166. doi:10.1111/j.1467-8691.2010.00559.x

Chang, Y. (2013). Student technological creativity using online problem-solving activities. International Journal of Technology and Design Education, 23(3), 803-816. doi:10.1007/s10798-012-9217-5

Chen, J. C. W. (2012). A pilot study mapping students' composing strategies: implications for teaching computer-assisted composition. Research Studies in Music Education, 34(2), 157-171. doi:10.1177/1321103X12465515

Chong, S. X., \& Lee, C. S. (2012). Developing a pedagogical-technical framework to improve creative wri- ting. Education Technology Research Development, 60(4), 639-657. doi:10.1007/s11423-012-9242-9

Christ, O., Weber, C., \& Sato, T. (2012). Evaluation of fostering students' creativity in preparing aided recalls for revision courses using electronic revision and recapitulation tools 2.0. Behaviour \& Information Technology, 31(8), 791-797. doi:10.1080/0144929X.2011.653985

Coll, C., \& Monereo, C. (2010). Educação e aprendizagem no século XXI: novas ferramentas, novos cenários, novas finalidades. In C. Coll, \& C. Monereo (Eds.), Psicologia da educação virtual: aprender e ensinar com as tecnologias da informação e da comunicação (pp. 15-46, N. Freitas, trad.). Porto Alegre, RS: Artmed.

Cropley, A. J. (2005). Creativity in education \& learning: a guide for teachers and educators. London: RoutledgeFalmer.

Csikszentmihalyi, M. (1999). Implications of a systems perspective for the study of creativity. In R. J. Sternberg (Ed.), Handbook of creativity (pp. 313-335). New York, NY: Cambridge University Press.

Cysneiros, P. G. (1999). Novas tecnologias na sala de aula: melhoria do ensino ou inovação conservadora? Informática Educativa, 12(1), 11-24. Recuperado de http://www.colombiaaprende.edu.co/html/mediateca/1607/articles-106213_archivo.pdf

Dale, C. (2008). iPods and creativity in learning and teaching: an instructional perspective. International Journal of Teaching and Learning in Higher Education, 20(1), 1-9. Recuperado de http://www.isetl. org/ijtlhe/pdf/IJTLHE20(1).pdf

Eyadat, W. M., \& Eyadat, Y. A. (2010). Instructional technology and creativity among university students: the missing link. World Journal on Educational Technology, 2(2), 87-99. Recuperado de http://sproc.org/ archives/index.php/wjet/article/view/164/pdf_13

Ferguson, R. (2011). Meaningful learning and creativity in virtual worlds. Thinking Skills and Creativity, 6(3), 169-178. doi:10.1016/j.tsc.2011.07.001

Frossard, F., Barajas, M., \& Trifonova, A. (2012). A learner-centred game-design approach: impacts on teachers' creativity. Digital Education Review, 21, 13-22. Recuperado de http://www.raco.cat/index. $\mathrm{php} / \mathrm{DER} /$ article/view/254208

Gangadharbatla, H. (2010). Technology component: a modified systems approach to creative thou- 
ght. Creativity Research Journal, 22(2), 219-227. doi: 10.1080/10400419.2010.481539

Goulah, J. (2007). Village voices, global visions: digital video as a transformative foreign language learning tool. Foreign Language Annals, 40(1), 62-78. doi:10.1111/j.1944-9720.2007.tb02854.x

Hall, T. (2012). Digital renaissance: the creative potential of narrative technology in education. Creative Education, 3(1), 96-100. doi:10.4236/ce.2012.31016

Jang, S. J. (2009). Exploration of secondary students' creativity by integrating web-based technology into an innovative science curriculum. Computers \& Education, 52(1), 247-255. doi:10.1016/j.compedu.2008.08.002

Johnson-Leslie, N. A. (2008-9). Comparing the efficacy of an engineered-based system (College Livetext) with an off-the-shelf general tool (hyperstudio) for developing electronic portfolios in teacher education. Journal of Educational Technology Systems, 37(4), 385-404. doi:10.2190/ET.37.4.d

Joly, M. C. R. A., Silva, B. D., \& Almeida, L. S. (2012). Avaliação das competências docentes para utilização das tecnologias digitais da comunicação e informação. Currículo sem Fronteiras, 12(3), 83-96. Recuperado de http://www.curriculosemfronteiras.org/vol12iss3articles/joly-silva-almeida.pdf

Joly, M. C. R. A., Berberian, A. A., Andrade, R. G., \& Teixeira, T. C. (2010). Análise de dissertações e teses em Avaliação Psicológica disponíveis na BVS-Psi Brasil. Psicologia Ciência e Profissão, 30(1), 174-187. doi:10.1590/S1414-98932010000100013

Kaufman, J.C., \& Beghetto, R. A. (2013). In praise of Clark Kent: creative metacognition and the importance of teaching kids when (not) to be creative. Roeper Review, 35(3), 155-165. doi:10.1080/02783193.2013.799413

Kenski, V. M. (2011). Educação e tecnologias: o novo ritmo da educação (8a ed.). Campinas, SP: Papirus.

Lalueza, J. L., Crespo, I., \& Camps, S. (2010). As tecnologias da informação e comunicação e os processos de desenvolvimento e socialização. In C. Coll, \& C. Monereo (Eds.), Psicologia da educação virtual: aprender e ensinar com as tecnologias da informação e da comunicação (pp. 47-65). Porto Alegre, RS: Artmed.

Leng, E. Y., Ali, W. Z. W., Mahmud, R., \& Baki, R. (2010). Computer games development experience and appreciative learning approach for creati- ve process enhancement. Computers \& Education, 55(3),1131-1144. doi:10.1016/j.compedu.2010.05.011

Lewis, T. (2009). Creativityin technology education: providing children with glimpses of their inventive potential. International Journal of Technology and Design Education, 19(3), 255-268. doi:10.1007/s10798-008-9051-y

Loveless, A. (2007). Creativity, technology and learning: a review of recent literature. Recuperado de http:// citeseerx.ist.psu.edu/viewdoc/download?doi=10.1.1.392.2297\&rep=rep1\&type=pdf

Lubart, T. (2007). Psicologia da criatividade. Porto Alegre, RS: Artmed.

Magnuson , M. L. (2013). Web 2.0 and information literacy instruction: aligning technology with ACRL standards. The Journal of Academic Librarianship, 39(3), 244-25. doi:10.1016/j.acalib.2013.01.008

Martins, R. X. (2005). Competências em tecnologia da informação no ambiente escolar. Psicologia Escolar e Educacional, 9(2), 323-326. doi:10.1590/S1413-85572005000200016

Mellor, L. (2008). Creativity, originality, identity: investigating computer-based composition in the secondary school. Music Education Research, 10(4), 451-472. doi:10.1080/14613800802547680

Mueller, J. S., Melwani, S., \& Goncalo, J. A. (2010). The bias against creativity: why people desire but reject creative ideas. Psychological Science, 23(1), 13-17. doi:10.1177/0956797611421018

Naeini, F. H., \& Masood, M. (2012). Effect of educational computer games on student creativity. Research Journal of Applied Sciences, Engineering and Technology, 4(23), 5280-5284. Recuperado de http:// pakacademicsearch.com/pdf-files/eng/392/52805284\%20Vol.\%204,\%20Issue\%2023\%202012.pdf

Nakano, T. C. (2011). Programas de treinamento em criatividade: conhecendo as práticas e resultados. Psicologia Escolar e Educacional, 15(2), 311-322. doi:10.1590/S1413-85572011000200013

Nakano, T. C., \& Wechsler, S. M. (2012). Criatividade: definições, modelos e formas de avaliação. In C. S. Hutz (Ed.), Avanços em avaliação psicológica e neuropsicológica de crianças e adolescentes II (pp. 327-361). São Paulo, SP: Casa do Psicólogo.

Navarrete, C. C. (2013). Creative thinking in digital game design and development: a case study. Computers \& Education, 69, 320-331. doi:10.1016/j.compedu.2013.07.025 
Nielsen, L. D. (2013). Developing musical creativity: student and teacher perceptions of a high school music technology curriculum. Update: Applications of Research in Music Education, 31(2), 54-62. doi:10.1177/8755123312473610

Öngün, E., Altas, D., \& Demirag, A. (2011). A study of $8^{\text {th }}$ graders' perceptions of socio-cultural perspective of creativity by using information technology tools in realization of homework goals. The Turkish Online Journal of Educational Technology, 10(3), 21-26. Recuperado de http://www.tojet.net/articles/v10i3/1033.pdf

Ott, M., \& Pozzi, F. (2012). Digital games as creativity enablers for children. Behaviour \& Information Technology, 31(10), 1011-1019. doi:10.1080/0144929X.2010.526148

Patera, M., Draper, S., \& Naef, M. (2008). Exploring Magic Cottage: a virtual reality environment for stimulating children's imaginative writing. Interactive Learning Environments, 16(3), 245-263. doi:10.1080/10494820802114093

Pearson, M. (2005). Splitting clips and telling tales: students interactions with digital video. Education and Information Technologies, 10(3), 189-205. doi:10.1007/s10639-005-3000-0

Rasinen, A., Virtanen, S., Endepohls-Ulpe, M., Ikonen, P., Ebach, J., \& Stahl-von Zabern, J. (2009). Technology education for children in primary schools in Finland and Germany: different school systems, similar problems and how to overcome them. International Journal of Technology and Design Education, 19(4), 367-379. doi:10.1007/s10798-009-9097-5

Renzulli, J. S. (2005). Applying gifted education pedagogy to total talent development for all students. Theory into Practice, 44(2), 80-89. Recuperado de https://www.jstor. org/stable/3497026?seq=1\#page_scan_tab_contents

Sawyer, R. K. (2012). Explaining creativity: the science of human innovation (2a ed.). New York, NY: Oxford University Press.

Silva, B., Araújo, A., Vendramini, C., Martins, R., Piovazan, N., Prates, .. . Joly, M. C. (2014). Aplicação e uso de tecnologias digitais pelos professores do ensino superior no Brasil e em Portugal. Educação, Formação \& Tecnologias, 7(1), 3-18. Recuperado de http:// www.eft.educom.pt/index.php/eft/article/view/424

Smith, J. M. (2012). The beyonder app: designing a website and a mobile application for teachers to integrate the Torrance Incubation Model into classroom content.
Recuperado de http://digitalcommons.buffalostate. edu/creativeprojects/147/

Starcic, A. I. (2010). Educational technology for the inclusive classroom. The Turkish Online Journal of Educational Technology, 9(3), 26-37. Recuperado de http://www.tojet.net/articles/v9i3/933.pdf

Sternberg, R. J., \& Lubart, T. I. (1991). An investment theory of creativity and its development. Human Development, 34(1), 1-31. doi:10.1159/000277029

Tsai, C., \& Liang, J. (2009). The development of science activities via on-line peer assessment: the role of scientific epistemological views. Instructional Science, 37(3), 293-310. doi:10.1007/s11251-007-9047-0

Valente, J. A. (2005). Pesquisa, comunicação e aprendizagem com o computador: o papel do computador no processo ensino-aprendizagem. In M. E. B. Almeida, \& J. M. Moran (Eds.), Integração das tecnologias na educação: salto para o futuro (pp. 22-31). Brasília, DF: Ministério da Educação.

Valente, J. A. (2014). A comunicação e a educação baseada no uso das tecnologias digitais de informação e comunicação. Revista UNIFESO - Humanas e Sociais, 1(1), 141-166. Recuperado de file:///C:/Users/ User/Downloads/17-60-1-PB.pdf

Walsh, C. S. (2007). Creativity as capital in the literacy classroom: youth as multimodal designers. Literacy, 41(2), 79-85. doi:10.1111/j.1467-9345.2007.00461.x

Ward, C. J. (2009). Musical exploration using ICT in the middle and secondary school classroom. International Journal of Music Education, 27(2), 154-168. doi:10.1177/0255761409102323

Wechsler, S. M., \& Souza, V. L. T. (Eds.). (2011). Criatividade e aprendizagem. caminhos e descobertas em perspectiva internacional. São Paulo, SP: Loyola.

\section{Daniela Vilarinho-Rezende}

Doutoranda em Desenvolvimento Humano e Saúde pela Universidade de Brasília, Brasília - DF. Brasil.

E-mail: dvilarinho.rezende@gmail.com

\section{Clarissa Nogueira Borges}

Mestrado em Desenvolvimento Humano e Saúde pela Universidade de Brasília, Brasília - DF. Brasil.

E-mail: claranogborges@hotmail.com 


\section{Denise de Souza Fleith}

Doutora em Psicologia Educacional pela University of Connecticut, Storrs-CT,EUA. Docente doDepartamento de Psicologia Escolar e do Desenvolvimento da Universidade de Brasília, Brasília - DF. Brasil.

E-mail: fleith@unb.br

Maria Cristina Rodrigues Azevedo Joly

Doutora em Psicologia da Aprendizagem e do Desenvolvimento Humano pela Universidade de São Paulo, São Paulo - SP. Pesquisadora colaboradora sênior do Programa de Pós-Graduação em Desenvolvimento Humano e Saúde da Universidade de Brasília, Brasília - DF. Brasil.

E-mail:mcrisjoly@gmail.com
Endereço para envio de correspondência:

SQN 205, Bloco J, Apt. 401, Asa Norte, Brasília - DF CEP: 70843-100

Recebido 22/09/2014

Aprovado 19/10/2016

Received 09/22/2014

Approved 10/19/2016

Recibido 22/09/2014

Aceptado 19/10/2016

Como citar:Vilarinho-Rezende, D., Borges, C. N., Fleith D. S., Joly, M. C. (2016). Relação entre tecnologias da informação e comunicação e criatividade: revisão da literatura. Psicologia: Ciência e Profissão, 36(3): 877-892. doi:10.1590/1982-3703001342014

How to cite: Vilarinho-Rezende, D., Borges, C. N., Fleith D. S., Joly, M. C. (2016). Relationship between information and communication technologies and creativity: literature review. Psicologia: Ciência e Profissão, 36(3): 877-892. doi:10.1590/1982-3703001342014

Cómo citar:Vilarinho-Rezende, D., Borges, C. N., Fleith D. S., Joly, M. C. (2016). Relación entre las tecnologías de la información y comunicación y creatividad: revisión de la literatura. Psicologia: Ciência e Profissão, 36(3): 877-892. doi:10.1590/1982-3703001342014 